\title{
Improvements in data quality for decision support in Intensive Care
}

\author{
Filipe Portela ${ }^{1}$, Marta Vilas-Boas ${ }^{1}$, Manuel Filipe Santos ${ }^{1}$ and Fernando Rua ${ }^{2}$ \\ ${ }^{1}$ University of Minho, Guimarães, Portugal \\ ${ }^{2}$ Hospital de Santo António, Porto, Portugal \\ ${ }^{1}$ acfp, mvb, mfs\} @dsi.uminho.pt, \\ ${ }^{2}$ fernandorua.scilhgsa.min-saude.pt
}

\begin{abstract}
Nowadays, there is a plethora of technology in hospitals and, in particular, in intensive care units. The clinical data produced everyday can be integrated in a decision support system in real-time to improve quality of care of the critically ill patients. However, there are many sensitive aspects that must be taken into account, mainly the data quality and the integration of heterogeneous data sources. This paper presents INTCare, an Intelligent Decision Support System for Intensive Care in real-time and addresses the previous aspects, in particular, the development of an Electronic Nursing Record and the improvements in the quality of monitored data.
\end{abstract}

Keywords: Patient ID, Data Quality, Data Acquisition, Real-Time, Null Values, Electronic Nursing Records.

\section{Introduction}

With the increasing presence of electronic health records (EHR) [1] [2], Information Technology (IT) may be a great ally for increasing quality and efficiency of health care, by providing the right information at the right time, to the right persons [3] [4] . Integration of information systems throughout the hospital and, in particular, the Intensive Care Unit (ICU) enables information sharing, communication, collaboration and coordination among the medical staff [5].

Furthermore, in a sensitive setting like the ICU, where patients' clinical condition is critical and their lives are at risk, there is a pressure to make fast and often critical decisions with incomplete information [6]. Consequently, Paper Based Nursing Records (PBNR) are a big constrain in terms of decision support because access to information may be extremely slow [7]. Apart from the paper based issues, there are also distributed data sources that must be integrated for faster and reliable access and availability of information [8].

This paper presents the INTCare system and the Electronic Nursing Record (ENR) developed to integrate all the data sources related to the ICU into one web-based userdriven application and the redesign of the information flow throughout the ICU and the hospital Information System (IS), thanks to its interoperability features [9].

This article is divided in introduction, developed work, results, discussion and conclusion. In the developed work we present the adjustments made to obtain better data quality from the Bedside Monitors (BM). In results, it is made a comparison of results between the year 2009 and the present year, followed by a discussion and a conclusion to this paper. 


\section{Background}

The goal of INTCare [10] is to develop an Intelligent Decision Support System (IDSS) for the ICU of Hospital de Santo António (HSA) in Porto, Portugal and the motivation underneath is the improvement of health care for critically ill patients, particularly the prediction of organ failure and outcome.

During the development and implementation of the system, it came to our attention that the large amount of data monitored and collected daily regarding the patients' clinical condition are underused; often, essential data are stored only in paper format, which is not compatible with the need for fast and reliable diagnosis and up-to-date information, which are crucial factors in intensive care [11]. Moreover, even the electronic data gathered and stored are underused, for it is not integrated and interrelated; its use in the context of a Decision Support System (DSS) in real-time is dependent on its integration and availability to whom may require it. As an example, although the patients' vital signs are continuously monitored and electronically registered, they can only show the patients' clinical evolution, leading to a re-active attitude from doctors.

Ideally, these data should be integrated with other sources of information to develop and use prediction models that would allow doctors to have a pro-active attitude towards the patients care. The ENR not only provides the medical staff the information they need, when it is necessary, but also makes possible to use that data for knowledge discovery and prediction models to support doctors' decision process in real-time [12]. Decision models will also provide suggestions for therapeutic and medical treatment, according to the predicted state of the patients.

\section{Electronic Nursing Record}

Since the last presentation [13], the ENR has suffered a set of alterations regarding its architecture, features, appearance and functionalities. These modifications are presented in the next topics.

\subsection{Description}

The ENR is a web based touch-screen system that enables communication with other platforms among the hospital and performs a set of tasks that support the activities of doctors and nurses on ICU, thanks to the interoperability of the hospital IS [9].

This application was developed based on the PBNR and throughout its evolution, we have added some features and functionalities in order to simplify the work in the hospital and promote dematerialization of processes.

\subsection{Data Acquisition Architecture}

The ENR is a part of the data acquisition and data entry subsystems, two of five subsystems of INTCare [12]. These subsystems are responsible for all activities of data acquisition and data storage and gather all the required data into a data warehouse [13]. 
This architecture contemplates the data acquisition from three sources and, regarding the information input, it is done either automatically (BM and Lab Results (LR)) or automatically and manually (nursing records). The adjustments made to the system were the addition of one more data source and the creation of two more agents that enable information storage in the database (DB).

\subsection{ENR - Features}

Table 1 shows the differences between the ICU situation in 2009 with PBNR and 2010 with ENR, taking into account the monitoring and documentation tasks.

Previously, some features could only be monitored (e.g. vital signs from BM) and others could only be documented (e.g. LR). For the procedures, the two tasks could be done. In 2010, with the ENR, it is possible to monitor and document online all the common tasks of the ICU.

Table 1. ENR - Features

\begin{tabular}{|c|c|c|c|c|}
\hline \multirow{2}{*}{ Features } & \multicolumn{2}{|c|}{2009} & \multicolumn{2}{|c|}{2010} \\
\hline & Monitoring & Documentation & Monitoring & Documentation \\
\hline Nursing Record & $x$ & PDF & $\sqrt{ }$ & $\mathrm{V}$ \\
\hline Vital Signs & $\sqrt{ }$ & $x$ & $\sqrt{ }$ & $\sqrt{ }$ \\
\hline HEB & $\sqrt{ }$ & $x$ & $\mathbf{v}$ & $\sqrt{ }$ \\
\hline Ventilations & $\sqrt{ }$ & $x$ & $\sqrt{ }$ & $\sqrt{ }$ \\
\hline Procedures & $\sqrt{ }$ & $\boldsymbol{v}$ & $\boldsymbol{v}$ & $\sqrt{ }$ \\
\hline Lab Results & $x$ & PDF & $\sqrt{ }$ & $\sqrt{ }$ \\
\hline Adverse Events & N & 3 & $\sqrt{ }$ & V \\
\hline
\end{tabular}

\subsection{ENR - Functionalities}

Table 2 shows the operations of each functionality (e.g. in the nursing records it is possible to write, read and validate the values in automatic (A) or manual (M) mode).

Table 3 presents other functionalities of the application regarding its users (doctors and nurses).

Table 2. Operations on ENR

\begin{tabular}{|c|c|c|c|c|c|}
\hline \multirow{2}{*}{ Functionalities } & \multicolumn{2}{|c|}{ Write } & \multirow{2}{*}{$\begin{array}{c}\text { Read } \\
\text { Possible }\end{array}$} & \multicolumn{2}{|c|}{ Validate / Correct } \\
\hline & Possible & Type & & Possible & Type \\
\hline Nursing Record & V & $A \& M$ & $\sqrt{ }$ & $\sqrt{ }$ & $A \& M$ \\
\hline Vital Signs & V & $A \& M$ & $\sqrt{ }$ & V & $A \& M$ \\
\hline HEB & $\boldsymbol{V}$ & $A \& M$ & $\sqrt{ }$ & $\boldsymbol{V}$ & $A \& M$ \\
\hline Ventilations & $\boldsymbol{V}$ & $A \& M$ & $\sqrt{ }$ & V & $A \& M$ \\
\hline Procedures & V & $\mathrm{M}$ & V & V & $\mathrm{M}$ \\
\hline Lab Results & - & - & $\sqrt{ }$ & - & - \\
\hline Adverse Events & $\boldsymbol{V}$ & $A \& M$ & $\sqrt{ }$ & $\boldsymbol{V}$ & $\mathrm{M}$ \\
\hline HER & $\mathbf{V}$ & $A \& M$ & $\sqrt{ }$ & V & $A \& M$ \\
\hline Medical Requests & $x$ & - & v & - & - \\
\hline
\end{tabular}


Table 3. Others Functionalities

\begin{tabular}{ll}
\hline \multicolumn{1}{c}{ Application } & \multicolumn{1}{c}{ To User } \\
\hline Auto / Manual Refresh and Save & User login \\
Show PID Information & Block edition and validate hour \\
Vital Signs Charts (minute, hour, day) & Responsible to validate data \\
Other Charts (adverse events, lab results ...) & Friendly interface \\
Links to another application & Easy to use \\
Data is confidential and secure & Touch-Screen \\
Show old data on DB (patient History) & Web Browser \\
\hline
\end{tabular}

\section{Results}

The development of the ENR was a required step to support the development and use prediction and decision models in real-time. It makes possible that all information necessary to achieve those goals is in electronic format and also contributes to a decrease of errors like unidentified patients, increases the system performance and enables more data storage and validation. With this progress we expect to have better results in the performance of the ICU tasks, less errors, more communication, as well as guarantee the users' satisfaction.

\subsection{Problems and Improvements}

During our work in the ICU, we detected various problems regarding the monitored data that required attention:

- Lack of identification (ID) of some patients;

- High number of incorrect or missing values;

- Regular failures of the data collecting system;

- Disconnected sensors;

And also a big constrain for a system in real-time, the presence of important information on paper records. To address these problems we performed some alterations:

- Creation of an intelligent agent that ensures the smooth yet robust performance of the entire process of data monitoring and data acquisition in real-time;

- Development of the ENR;

- Automatic storage of data in the DB;

- Recovery of data monitored without patients ID.

\subsection{Data Quality}

We analyzed some aspects regarding the data collected in the ICU in the same period of time in 2009 and 2010 and the results are shown in Table 4. 
Table 4. Information about data collected

\begin{tabular}{lrr}
\hline \multicolumn{1}{c}{ Features } & $\mathbf{2 0 0 9}$ & $\mathbf{2 0 1 0}$ \\
\hline Collecting period & 3 months & 3 months \\
Number of patients & 37 patients (F:15) & 55 patients (F:21) \\
Patients 'age (avg.) & 56 years and 100 days & 57 years and 190 days \\
Patients' length of stay (avg.) & 5 days and 10 hours & 2 days and 20 hours \\
Number of patients per day (avg.) & 3,66 & 3,58 \\
DB records & $\sim 250$ thousands & $\sim 500$ thousands \\
Acquisition time (avg.) & 1 time per minute & 1 time per minute \\
Number of collected hours & 1412 hours in 68 days & 1670 hours in 74 days \\
\hline To analyze the data quality we selected the four physiologic parameters more \\
monitored in Intensive care [14], calculated the difference between systolic and \\
diastolic blood pressure, counted the number of null values (
\end{tabular}

Table 5) and the values out of range (

Table 6).

The collected values relate to 3 months of 2009 (Jan. - Mar.) and 3 months of 2010 (Feb. - Apr.). For all cases we counted the number of occurrences per hour and patient, the total occurrences for each 3 months and the percentage of values in the three months that were out of range or null.

Table 5. Number of null values for monitored parameters

\begin{tabular}{|c|c|c|c|c|c|c|c|}
\hline \multirow[b]{2}{*}{$\begin{array}{l}\text { Monitored } \\
\text { Parameters }\end{array}$} & \multirow[b]{2}{*}{$\begin{array}{c}\text { Normality } \\
\text { Range }\end{array}$} & \multicolumn{3}{|c|}{ Number of null records 2009} & \multicolumn{3}{|c|}{ Number of null records 2010} \\
\hline & & $\begin{array}{l}\text { Hour / } \\
\text { patient }\end{array}$ & 3 Months & Total & $\begin{array}{l}\text { Hour / } \\
\text { patient }\end{array}$ & 3 Months & Total \\
\hline Heart Rate & {$[40-150]$} & 1,0 & 5419 & $2,20 \%$ & 0 & 0 & 0 \\
\hline $\mathrm{SpO}_{2}$ & $>=90$ & 3,7 & 19478 & $7,85 \%$ & c & 0 & 0 \\
\hline ART MEAN & {$[60-140]$} & 2,5 & 13170 & $5,30 \%$ & 0 & 0 & 0 \\
\hline CVP & {$[2-12]$} & 6,6 & 35049 & $14,15 \%$ & c & 0 & 0 \\
\hline$\Delta$ Syst - Dias 1 & $>=30$ & - & - & - & r & - & - \\
\hline
\end{tabular}

Table 6. Number of out of range values for monitored parameters

\begin{tabular}{|c|c|c|c|c|c|c|c|}
\hline \multirow[b]{2}{*}{$\begin{array}{l}\text { Monitored } \\
\text { Parameters }\end{array}$} & \multirow[b]{2}{*}{$\begin{array}{l}\text { Normality } \\
\text { Range }\end{array}$} & \multicolumn{3}{|c|}{ Out of range records 2009} & \multicolumn{3}{|c|}{ Out of range records 2010} \\
\hline & & $\begin{array}{l}\text { Hour / } \\
\text { patient }\end{array}$ & 3 Months & Total & $\begin{array}{l}\text { Hour / } \\
\text { patient }\end{array}$ & 3 Months & Total \\
\hline Heart Rate & [40 -150] & 0,2 & 1115 & $0,45 \%$ & 0,14 & 861 & $0,69 \%$ \\
\hline $\mathrm{SpO}_{2}$ & $>=90$ & 1,8 & 9402 & $3,79 \%$ & 0,35 & 1875 & $1,16 \%$ \\
\hline ART MEAN & {$[60-140]$} & 2,1 & 11177 & $4,51 \%$ & 0,82 & 5220 & $4,29 \%$ \\
\hline CVP & [2-12] & 20,6 & 109065 & $43,96 \%$ & 10,94 & 69581 & $51,82 \%$ \\
\hline$\Delta$ Syst - Dias1 & $>=30$ & 2,6 & 14034 & $5,66 \%$ & 1,2 & 7608 & $6,86 \%$ \\
\hline
\end{tabular}

In conclusion, with the ENR, it is possible to improve the data quality and reduce the number of unidentified patients in the monitoring system. The following graphics (Chart 2, Chart 3, Chart 1) show the improvements achieved with new configuration of the data acquisition system and the notifications on ENR whenever patients aren't identified on the monitoring systems (either because sensors are disconnected or patients aren't identified in the system). 
By comparing the two years analyzed (2009 without ENR and 2010 with ENR) we conclude that the number of patients without ID in the BM decreased.

A further analysis tried to verify in what conditions the data monitored was lost because of non identified patients. To do so, we divided each chart in three categories:

1. All days of hospitalization were monitored (ALL);

2. Fail of one day of hospitalization (Miss 1);

3. Fail for more than one day (Miss + ).

The sources and the alteration that we made to each time series $(2009,2010$, April) is represented on Table 7.

Initially, with the PBNR, there was no notification about patients without ID. Accordingly, we developed a feature in the ENR that alerts the users about the patients without identification in the system.

Furthermore, to guarantee the system's functionality and robustness and to mitigate possible failures in the data collecting and storage systems, the system is scheduled to restart every hour, so that if the system inadvertently stops, it automatically starts in next hour, minimizing the loss of data.

Table 7. Modifications in each time series

\begin{tabular}{lccc}
\hline & 2009 & 2010 & April 2010 \\
\hline PBNR & $\sqrt{ }$ & $\sqrt{ }$ & $\mathrm{V}$ \\
ENR & $\boldsymbol{V}$ & $\mathrm{V}$ & $\mathrm{V}$ \\
System Configuration & $\boldsymbol{V}$ & $\mathrm{V}$ \\
\hline
\end{tabular}

2009

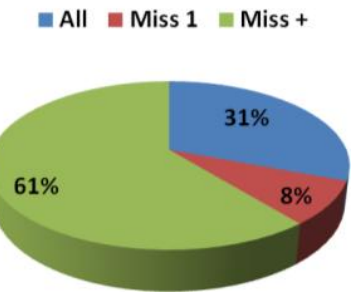

Chart 2. PID in 2009
2010

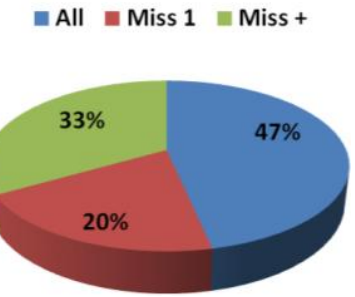

Chart 3. PID in 2010
APRIL

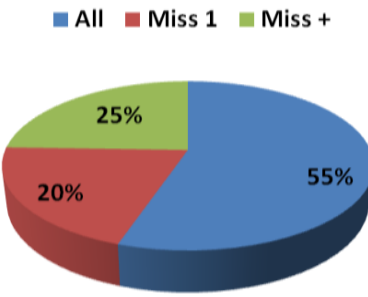

Chart 1. PID in April

\section{Discussion}

\section{As shown in}

Table 5, the number of null values in 2010 is 0 . This improvement is due to the modification implemented in the data acquisition agent, which only receives data if a value isn't 0 . For example, if the sensors fail and the acquisition system continues to work, it doesn't receive values. In such case, the nursing staff is notified by the ENR that some sensor is disconnected and they shall proceed to repair this fault. With this simple operation it is possible to reduce null data on the DB (

Table 5). 
Another problem regarding the data quality is the presence of out of range values. Its validation is a much more complex issue, because in an ICU environment, it is expected that critically ill patients may have out of range values of the physiological parameters monitored. In

Table 6 we can verify that the results are similar in the two years analyzed, however they show a slight improvement. For example, the results of Pulse Oximeter Oxygen Saturation $\left(\mathrm{SpO}_{2}\right)$ collected by the system in 2010 are better, i.e., $98.84 \%$ of the values are in normal range, which represents $2.5 \%$ more comparatively to 2009 .

Furthermore, we confirmed what the nursing staff of the ICU had suspected about the Central Venous Pressure (CVP) being the worst parameter analyzed in terms of data quality because it has had bad results throughout the years. In 2010 it has worsen in $8.10 \%$. At the moment, it is implemented a manual validation mode on the ENR for situations of out of range values, where nurses can confirm if an automatically collected value is correct or not. Regarding this feature, in the future, it will be created an intelligent agent to perform this task automatically.

Charts 1, 2 and 3 show the evolution of the presence of patients' ID information in the BM. These charts represent the number of days where the patients' ID is correctly inserted on data registers during a complete hospitalization. The most important change occurred with the implementation of the ENR and the notification of patients without identification. This led to an increase of $16 \%$ in the number of days monitored in 2009 (31\%) in comparison to $2010(47 \%)$.

As shown in the most recent chart of April 2010 (Chart 3), the number of correct days (ALL) increases. This is due to the alterations made on data acquisition system. $55 \%$ of the patients hospitalized in the ICU on April had all time monitored and 20\% failed only one day (Miss 1). At the moment, we can't obtain better results using this method because when patients arrive to the ICU, the primary concern is to patients' safety and, under such stressful circumstances, it is reasonable that nurses don't identify the patients in the monitoring system immediately [15].

\section{Conclusion and Future Work}

In this paper we presented the improvements of the INTCare system in the ICU of HSA, particularly the development of an ENR and changes in the monitoring system that led to an improvement of the quality of monitored data. When optimally implemented, ENR will be a potential benefit for intensive care. It enhances how patient data are registered, organized, accessed and viewed. Furthermore, it will permit simultaneous, remote access and integration with other information sources.

To mitigate the problem related with the patients' identification and to obtain a better accuracy, we will implement a Radio Frequency Identification (RFID) system [16] to automatically identify the patients by a tag attached to the patient's body. The system is in continuous development, tests and improvements. This is an important factor for a real-time IDSS that predicts organ failure and outcome relying on all the information about a patient clinical condition. 


\section{References}

1. Häyrinen, K., Saranto, K., Nykänen, P.: Definition, structure, content, use and impacts of electronic health records: A review of the research literature. International journal of medical informatics 77, 291-304 (2008)

2. Timmermans, S.: Health Care Technology. In: Neil, J.S., Paul, B.B. (eds.) International Encyclopedia of the Social \& Behavioral Sciences, pp. 6544-6550. Pergamon, Oxford (2001)

3. Handel, D.A., Hackman, J.L.: Implementing Electronic Health Records in the Emergency Department. The Journal of Emergency Medicine 38, 257-263 (2010)

4. Nowinski, C.J., Becker, S.M., Reynolds, K.S., Beaumont, J.L., Caprini, C.A., Hahn, E.A., Peres, A., Arnold, B.J.: The impact of converting to an electronic health record on organizational culture and quality improvement. International Journal of Medical Informatics 76, S174-S183 (2007)

5. Meyfroidt, G.: How to implement information technology in the operating room and the intensive care unit. Best Practice \& Research Clinical Anaesthesiology 23, 1-14 (2009)

6. De Turck, F., Decruyenaere, J., Thysebaert, P., Van Hoecke, S., Volckaert, B., Danneels, C., Colpaert, K., De Moor, G.: Design of a flexible platform for execution of medical decision support agents in the intensive care unit. Computers in Biology and Medicine 37, 97-112 (2007)

7. Sado, A.S.: ELECTRONIC MEDICAL RECORD IN THE INTENSIVE CARE UNIT. Critical Care Clinics 15, 499-522 (1999)

8. Herasevich, V., Keegan, M.T., Tines, D., Malinchoc, M.M., Hanson, A.C., Katyal, P., Hubmayr, R.D., Afessa, B., Gajic, O.: "ICU of the future": informatics infrastructure for syndrome surveillance, decision support, data mining, and modeling of critical illness. Journal of Critical Care 22, 340-340 (2007)

9. Abelha, A., Machado, J., Santos, M., Allegro, S., Rua, F., Paiva, M., Neves, J.: Agency for Integration, Diffusion and Archive of Medical Information. In: Conference Agency for Integration, Diffusion and Archive of Medical Information. (Year)

10. Santos, M.F.e.a.: Information Modeling for Real-Time Decision Support in Intensive Medicine. Proceedings of the 8th Wseas International Conference on Applied Computer and Applied Computational Science (2009)

11. Garg, A.X., Adhikari, N.K.J., McDonald, H., Rosas-Arellano, M.P., Devereaux, P.J., Beyene, J., Sam, J., Haynes, R.B.: Effects of computerized clinical decision support systems on practitioner performance and patient outcomes: a systematic review. Jama 293, 1223 (2005)

12. Santos, M.F., Vilas-Boas, M., Machado, J., Neves, J., Silva, A., Rua, F., Salazar, M., Quintas, C., Cabral, A.F.: Intelligent Decision Support in Intensive Care Units - Nursing Information Requirements. (2009)

13. Santos, M.F., Portela, F., Vilas-Boas, M., Machado, J., Abelha, A., Neves, J.: Information Architecture for Intelligent Decision Support in Intensive Medicine. 8th WSEAS International Conference on APPLIED COMPUTER \&amp; APPLIED COMPUTATIONAL SCIENCE (ACACOS '09), vol. 8. WSEAS, Hangzhou, China, (2009)

14. Silva, Á.: Modelos de Inteligência Artificial na análise da monitorização de eventos clínicos adversos, Disfunção/Falência de órgãos e prognóstico do doente critico. Ciências Médicas, vol. Doutoramento, pp. 281. Universidade do Porto, Porto (2007)

15. Varshney, U.: Pervasive healthcare and wireless health monitoring. Mobile Networks and Applications 12, 113-127 (2007)

16. Westra, B.L.: Radio Frequency Identification. AJN The American Journal of Nursing 109, 34 (2009) 